\title{
CIRCULAC̦ÃO DE SABERES PSI E CONTROLE DAS CONDUTAS EM CURRÍCULOS DA EDUCAÇÃO FÍSICA
}

\author{
Clayton Cesar de Oliveira Borges* \\ Universidade de São Paulo (USP), São Paulo - SP, Brasil \\ Luciana Maria Viviani"* \\ Universidade de São Paulo (USP), São Paulo - SP, Brasil
}

RESUMO: Esta pesquisa examina como os currículos de Educação Física da rede municipal de Sorocaba são inseridos em uma rede de poderes e sustentados por determinados tipos de saberes. Analisamos três documentos curriculares, elaborados em 2008, 2010 e 2012, mediante o apoio do pensamento foucaultiano, especialmente das noções de enunciado e formação discursiva, e das contribuições dos estudos de currículo de orientação pós-crítica. A investigação se inicia pelo exame de enunciados referentes à tipologia de conteúdos de aprendizagem e, em seguida, aborda a organização curricular por competências e a gestão curricular. Por fim, indicamos como esses enunciados, de caráter nitidamente instrumental, constituem um campo de coexistências, alicerçados na formação discursiva da psicologia educacional. Palavras-chave: Currículo de Educação Física. Análise do discurso. Tipologia de conteúdos de aprendizagem. Organização curricular por competências.

\section{CIRCULATION OF KNOWLEDGE PSI AND BEHAVIOR CONTROL IN CURRICULUM OF PHYSICAL EDUCATION}

ABSTRACT: This research examines the results of insertion of the curriculum of Physical Education in the Sorocaba municipal network into a network of powers and supported by certain types of knowledge. We have analyzed

\footnotetext{
"Doutorando em Educação pela Faculdade de Educação da Universidade de São Paulo (FEUSP) e Mestre em Estudos Culturais pela Escola de Artes, Ciências e Humanidades (EACH/USP). Docente do curso de Licenciatura em Educação Física da FAC-São Roque. Pesquisador vinculado ao Grupo de Pesquisas em Educação Física Escolar da Faculdade de Educação da Universidade de São Paulo (GPEF-FEUSP). E-mail: < prof.claytonborges@gmail.com > . "“Doutora em Educação pela Faculdade de Educação da Universidade de São Paulo (FEUSP). Docente e pesquisadora do curso de Licenciatura em Ciências da Natureza e do Programa de Pós-Graduação em Estudos Culturais da Escola de Artes, Ciências e Humanidades da Universidade de São Paulo (EACH/USP). Líder do Grupo de Pesquisa Identidades Docentes e Culturas Profissionais (EACH/USP). E-mail: <lviviani@usp.br >.
} 
three curriculum documents, drafted in 2008, 2010 and 2012 through the support of Foucault's thought, especially the statement notions of discursive formation, and the contributions of curriculum studies of postcritical guidance. The research begins with the question analysis regarding the learning content typology and then addresses the curricular organization for skills and curriculum management. Finally, we indicate how these statements, of clearly instrumental character, compose a coexistences field, based on discursive formation of educational psychology.

Keywords: Curriculum of Physical Education. Discourse analysis Type of learning content. Curricular organization for skills.

\section{INTRODUÇ̃̃o}

O curriculo tem significados que vão muito além daqueles aos quais as teorias tradicionais nos confinaram. O curriculo é lugar, espaço, território. O currículo é relação de poder. O curriculo é trajetória, viagem, percurso. O currículo é autobiografia, nossa vida curriculum vitae: no currículo se forja nossa identidade. O currículo é texto, discurso, documento. O currículo é documento de identidade.

(Tomaz Tadeu da Silva) ${ }^{1}$

A ideia de currículo corporifica uma organização particular de conhecimentos. As teorias do currículo funcionam como um lugar de superposição de verdades, apoiadas, sobretudo, por discursos científicos, e possuem, como objetivo, a projeção de um tipo de pessoa desejável para determinada sociedade que, dependendo da vertente curricular, pode ser a pessoa racional do ideal humanista, a pessoa competitiva do modelo neoliberal ou a pessoa questionadora dos arranjos sociais existentes, referente às teorias críticas e pós-críticas (SILVA, 2011a). Em outros termos, as teorias do currículo objetivam a produção institucionalizada e massiva de identidades sociais.

Silva (2011a) aponta que os discursos empreendidos pelas teorias e autores sobre o que é o currículo acabam efetivamente se tornando o currículo, ou seja, tem efeito de realidade. A partir dessa concepção, se o currículo se basear numa determinada visão de sociedade, embora não seja um processo direto, mas sujeito a inúmeros fatores intervenientes, compreendemos que esses discursos atuam na subjetivação de professores, que poderão criar suas práticas pedagógicas mediante a concepção veiculada e, em consequência, haverá processos de subjetivação dos estudantes. 
As diferentes teorias do currículo disputam quais significações alcançarão uma maior circulação e aceitação no cenário educacional, em associação a redes de poder. Diversos teóricos da educação (CORAZZA, 1995; GORE, 2008; MACEDO, 2002; DIAS; LOPES, 2003) destacam que, apesar dos emergentes enfoques críticos e póscríticos que, entre outros, questionam as formas essencialistas de sujeito em voga em muitas propostas educacionais, são precisamente os regimes de verdade presentes nas "leis psicológicas" (Ó, 2011, p. 175) que têm sido prontamente acolhidos nas políticas de currículo atuais.

Corroborando o pensamento dos autores mencionados nas linhas acima no tocante à acepção de currículo e aos efeitos que podem exercer na subjetivação docente, além do predomínio dos discursos da psicologia educacional no cenário educacional, o presente estudo consiste em examinar como o currículo escolar é inserido numa rede de poderes e como é sustentado por determinados tipos de saberes.

Sob a inspiração da teorização pós-crítica, Neira e Nunes (2009) asseveram que, no campo da educação física escolar, analisar os saberes que sustentam a opção pedagógica é de substancial relevância, tendo em vista que essa iniciativa pode influenciar tanto os sujeitos que se pretende formar quanto as orientações didáticas mobilizadas na prática pedagógica. Intentamos, assim, contribuir para o aprofundamento teórico que poderá fornecer elementos para melhor compreender os saberes materializados na produção das políticas curriculares de Educação Física aqui investigadas.

A opção por tomar determinadas enunciações dos documentos curriculares em questão como corpus de pesquisa se deu, entre outros motivos, por conta do momento ímpar de produção de uma "nova" matriz curricular de todas as disciplinas escolares e de todos os níveis de ensino - infantil, fundamental e médio - da rede de ensino municipal de Sorocaba, que ocorreu no ano de 2012. Pretendemos descrever discursos consubstanciados em documentos curriculares de Educação Física dessa rede municipal, cujo interesse específico surgiu das inquietações de um dos autores deste estudo, que atua na educação básica lecionando esse componente curricular.

Perscrutamos em três documentos curriculares de Educação Física da rede municipal de Sorocaba enunciados relacionados à tipologia de conteúdos de aprendizagem (SOROCABA, 2008, 2010), à organização curricular por competências e à gestão curricular (SOROCABA, 2012), que constituem o principal parâmetro de ordenação curricular nos documentos examinados. O impresso 
curricular mais recente, elaborado no ano de 2012 por um professor de Educação Física da rede de ensino municipal de Sorocaba e com o assessoramento do Instituto Paradigma2, se baseou em dois outros documentos curriculares de Educação Física elaborados nos anos de 2008 e 2010. Estes foram produzidos, respectivamente, por um professor formador e um pequeno coletivo de professores dessa rede de ensino.

Dessa feita, consideramos pertinente a análise dos três impressos, a fim de verificar os saberes que os constituem e as possíveis aproximações entre eles ou, para fazer uso da linguagem foucaultiana, identificar e descrever enunciados e seus campos de coexistências (FOUCAULT, 2008).

Outro aspecto a ser destacado é o fato de que os dois primeiros impressos curriculares - elaborados exclusivamente para os anos iniciais do Ensino Fundamental - ocorreram em meio às atividades de formação continuada em serviço de professores de Educação Física da rede municipal de Sorocaba, realizadas quinzenalmente durante o período de 2006 a 2011, promovidas pelo Instituto Esporte e Educação (IEE) ${ }^{3}$. Tendo em vista a participação dos sujeitos que formularam os documentos curriculares aqui mencionados em tal formação, acreditamos que, em alguma medida, os pressupostos teóricos veiculados possam ter influenciado a construção dos documentos curriculares, conforme pontuaremos mais detalhadamente adiante.

Como suporte teórico, metodológico e analítico, apoiamonos em estudos de currículo, como aqueles desenvolvidos por Dias e Lopes (2003) e Macedo (2002). As autoras denominam de hibridismo cultural a multiplicidade de concepções curriculares presentes no cenário educacional atual. Entretanto, ao contrário do que inicialmente possa parecer, a hibridação não corresponde a um discurso democrático, pois "a hibridação mobiliza alguns sentidos e reprime ou apaga outros” (DUSSEL, 2002, p. 74).

Lopes e Macedo (2002) pontuam que, apesar dos emergentes enfoques críticos e pós-críticos que permeiam os estudos sobre currículo, as concepções construtivistas nas propostas curriculares ainda são hegemônicas. Em suas investigações, as autoras examinam o predomínio das enunciações oriundas da psicologia educacional nas políticas de currículo no Brasil, destacando o caráter instrumental desses enunciados, de modo a apontar associações entre o processo educacional e os ditames do mercado de trabalho. 
Silva (2011b) compreende que a representação por meio da linguagem é um processo de produção de significados, que atuam para tornar o mundo social conhecível e, assim, governável. O currículo também se vincula à produção de identidades sociais por intermédio dos processos de representação, pois as diferentes narrativas dos grupos sociais estão representadas no currículo de acordo com as relações de poder.

Algumas perspectivas tendem a identificar o conhecimento do currículo com o produzido no campo científico, artístico ou cultural. No entanto, Silva (2011b) adverte que esses conhecimentos são recontextualizados quando passam para o campo da educação, essas mudanças transformam o currículo em um processo de regulação moral. Essa regulação moral está historicamente ligada ao processo de escolarização de massa, tendo o currículo centralidade nesse processo. Compreender o vínculo entre currículo e regulação não significa sua aceitação, ao contrário, o objetivo é investigar as formas desse vínculo.

Também tomamos, como referência neste estudo, os pressupostos da arqueologia foucaultiana. Resumidamente, a arqueologia refere-se ao nível discursivo e sustenta que a verdade é dependente dos saberes de uma determinada época e cultura. Portanto, na arqueologia, a busca se direciona à reconstituição do processo de produção de um discurso tomado como verdade (CANDIOTTO, 2013).

A arqueologia foucaultiana não pretende ser o estudo de um acontecimento originário, senão de uma origem relativa, de uma irrupção. Também não coaduna com o sentido de escavação, pois se opõe à ideia de descobrir um suposto sentido oculto por detrás das palavras (FOUCAULT, 2008).

Em $A$ arqueologia do saber, Foucault desenvolve uma quantidade enorme de expressões e conceitos, por vezes, com diferentes significados, o que dificulta sistematizar uma terminologia detalhada do método arqueológico. Por questões de delimitação, optamos por fazer uso de algumas noções consideradas principais para as investigações das práticas discursivas que utilizam o enfoque arqueológico: o enunciado e a formação discursiva.

Os enunciados, mais do que unidades elementares do discurso, não equivalentes a proposições, frases, ou atos ilocutórios, são funções que se exercem em relação a diversas unidades. $\mathrm{O}$ enunciado "não é em si mesmo uma unidade, mas sim uma função que cruza um domínio de estruturas e de unidades possíveis e que faz com que apareçam, com conteúdos concretos, no tempo e no 
espaço" (FOUCAULT, 2008, p. 98). Desse modo, há enunciado em qualquer série de signos ou ainda eventualmente em um único signo, entretanto, um signo ou uma série de signos só se tornarão enunciados na medida em que seja possível descrever suas condições de existência, seu espaço de correlações com outros enunciados, suas materialidades e as regras que o controlam.

Uma apropriação da noção foucaultiana de enunciado e formação discursiva é oferecida por Fischer (1996, p. 105). Nas palavras da autora, descrever um enunciado compreende "apreendê-lo como acontecimento, como algo que irrompe num certo tempo, num certo lugar". Os enunciados, por sua vez, pertencem a uma formação discursiva, que está sempre relacionada a determinados campos de saber.

Foucault (2008, p. 132) denomina de formação discursiva a possibilidade de descrição de certo número de enunciados que podem definir determinada regularidade e instabilidade de sentidos no discurso. Ao descrever os enunciados, se procede à individualização de uma formação discursiva e, ao demarcar uma formação discursiva, se mostra algo dos enunciados, portanto, "a análise do enunciado e da formação discursiva são estabelecidas correlativamente", pois "a lei dos enunciados e o fato de pertencerem à formação discursiva constituem uma única e mesma coisa [...]".

Considerando que "o regime de materialidade ao qual os enunciados obedecem é da ordem da instituição" (NAVARROBARBOSA, 2004, p. 111), o campo educacional e, consequentemente, o currículo funcionam como local privilegiado para a materialidade do enunciado. No caso que diretamente nos interessa, examinamos enunciados referentes à tipologia de conteúdos de aprendizagem e a organização curricular por competências, discursos eminentes em políticas de currículo contemporâneas (MACEDO, 2002; DIAS; LOPES, 2003).

\section{AORGANIZAÇÃOCURRICULARMEDIANTEUMATIPOLOGIADECONTEÚDOSDEAPRENDIZAGEM}

Neste item, examinamos especificamente os currículos elaborados em 2008 e 2010, ambos intitulados de currículo mínimo, já que nesses dois documentos o enunciado que aparece com regularidade e praticamente exclusividade em quadros de atividades é a organização dos conteúdos de aprendizagem em tipos: conteúdos conceituais, procedimentais e atitudinais.

O modelo de organização de conteúdos de aprendizagem é citado ainda no currículo oficial de Educação Física: "a proposta 
curricular [...] adota também a classificação dos conteúdos curriculares em cognitivos, procedimentais e atitudinais" (SOROCABA, 2012, p. 19), entretanto, apesar dessa referência na parte introdutória do impresso curricular, ao longo do texto só há menções à organização dos conteúdos em competências e habilidades.

A proposta curricular de 2008 constitui-se de um quadro para cada ano ( $1^{\circ}$ ao $5^{\circ}$ ano), com as seguintes colunas: habilidades e competências, conceitual, procedimental e atitudinal. Há 10 linhas em cada quadro, sendo que, somente para o $1^{\circ}$ ano, há 11 itens. Enquanto as habilidades e competências e os conteúdos conceituais são apresentados brevemente, os outros conteúdos são mais numerosos e detalhados, como se observa abaixo. Por questões de restrição de espaço, apresentamos no Quadro 1 a seguir apenas alguns conteúdos do $1^{\circ}$ ano. Chama a atenção a similaridade dos textos, em todas as séries, com pequenas variações na especificidade ou complexidade de alguns conteúdos.

QUADRO 1

Excerto do currículo de 2008 para $01^{0}$ ano

\begin{tabular}{|l|l|l|l|}
\hline \multicolumn{1}{|c|}{$\begin{array}{c}\text { HABILIDADES E } \\
\text { COMPETÊNCIAS }\end{array}$} & \multicolumn{1}{|c|}{ CONCEITUAL } & \multicolumn{1}{c|}{ PROCEDIMENTAL } & ATITUDINAL \\
\hline $\begin{array}{l}\text { Demonstrar } \\
\text { capacidades } \\
\text { perceptivo-motoras } \\
\text { e sensório-motoras } \\
\text { básicas. }\end{array}$ & $\begin{array}{l}\text { Comportamento Motor } \\
\text { - capacidade perceptivo- } \\
\text { motora e sensório- } \\
\text { motora. }\end{array}$ & $\begin{array}{l}\text { Vivenciar experiências } \\
\text { diversificadas de } \\
\text { atividades que envolvam } \\
\text { as capacidades } \\
\text { perceptivo-motoras e } \\
\text { sensório-motoras básicas } \\
\text { (Antecipação, localização } \\
\text { espaço-temporal, ritmo, } \\
\text { lateralidade, percepção } \\
\text { tátil, auditiva e visual). }\end{array}$ & $\begin{array}{l}\text { Sentir, perceber e } \\
\text { reagir aos inúmeros } \\
\text { estímulos. }\end{array}$ \\
& & & \\
\hline
\end{tabular}

Fonte: SOROCABA, 2008, p. 2, grifos do documento.

$\mathrm{Na}$ proposta de 2010, também organizada em quadros $\left(1^{\circ}\right.$ ao $5^{\circ}$ ano), a primeira coluna é dedicada aos objetivos, enquanto as outras permanecem com igual teor. O número de objetivos é variável e crescente, conforme se sucedem as séries. Aqui, também há similaridade nos itens e os conteúdos procedimentais apresentamse mais numerosos e detalhados. Segue um exemplo referente ao $4^{\circ}$ ano no Quadro 2 abaixo. 
QUADRO 2

Excerto do currículo de 2010 para $04^{\circ}$ ano

\begin{tabular}{|c|c|c|c|}
\hline OBJETIVOS & CONCEITUAL & PROCEDIMENTAL & ATITUDINAL \\
\hline $\begin{array}{l}\text { - Identificar as funções } \\
\text { orgânicas relacionadas } \\
\text { às atividades físicas. }\end{array}$ & $\begin{array}{l}\text { - Conhecer e relacionar } \\
\text { as diferentes funções } \\
\text { orgânicas: Sistema } \\
\text { Cardio-respiratório } \\
\text { e sistema músculo } \\
\text { esquelético. } \\
\text { - Compreender a } \\
\text { importância da } \\
\text { Higiene Pessoal e Boa } \\
\text { alimentação como um } \\
\text { dos fatores para uma } \\
\text { melhor qualidade de } \\
\text { vida. }\end{array}$ & $\begin{array}{l}\text { - Aplicar os conceitos } \\
\text { sobre as funções } \\
\text { orgânicas às vivências } \\
\text { práticas e assuntos } \\
\text { que forem surgindo } \\
\text { necessidade de } \\
\text { esclarecimento. } \\
\text { - Praticar hábitos } \\
\text { saudáveis de Higiene } \\
\text { em situações de aula } \\
\text { tais como trazer toalha, } \\
\text { lavar mãos e rosto no } \\
\text { final das aulas. } \\
\text { - Adotar a prática } \\
\text { regular de hidratação } \\
\text { com uso de uma garrafa } \\
\text { de água durante as } \\
\text { aulas. }\end{array}$ & $\begin{array}{l}\text { - Perceber alteraç̃oses } \\
\text { do próprio corpo para } \\
\text { além da estrutura } \\
\text { corporal entendendo as } \\
\text { situações de repouso e } \\
\text { exercício através das } \\
\text { alterações a frequência } \\
\text { cardíaca, perda de água } \\
\text { e sais minerais. } \\
\text { - Apresentar bons } \\
\text { hábitos de alimentação } \\
\text { para uma boa qualidade } \\
\text { de vida. }\end{array}$ \\
\hline
\end{tabular}

Fonte: SOROCABA, 2010, p. 8, grifos do documento.

Presume-se, pois, que a organização do campo enunciativo que controla a tipologia de conteúdos de aprendizagem remete à noção de sujeito integral, isto é, aquele que necessita constantemente desenvolver todas as suas "potencialidades", a saber: as competências de ordem prática, cognitiva e comportamental. Mas qual é o lugar de onde advém essa proposta de organização de conteúdos de aprendizagem? Quais as condições de possibilidade e os significados atribuídos a esse enunciado?

Esmiuçando a temática no campo da educação física escolar, ao que tudo indica, os documentos curriculares que propõem essa sistematização dos conteúdos são os Parâmetros Curriculares Nacionais (PCNs) de Educação Física (BRASIL, 1997, 1998a, 1998b), como se pode observar no excerto a seguir:

Os conteúdos de aprendizagem serão apresentados dentro dos blocos, segundo sua categoria conceitual (fatos, princípios e conceitos), procedimental (ligados ao fazer), e atitudinal (normas, valores e atitudes), o que permite a identificação mais precisa das intenções educativas. Antes, porém, é conveniente se precaver 
dos perigos de compartimentalizar o que nunca se encontra separado na aprendizagem. Essas categorias são utilizadas para melhor clareza das diferentes dimensões que interferem nas aprendizagens, permitindo uma análise global para a diferenciação da abordagem metodológica. Nesse sentido, deve-se considerar que essas categorias de conteúdo (conceitual, procedimental, atitudinal) sempre estão associadas, mesmo que tratadas de maneira específica. (BRASIL, 1998b, p. 73-74)

A organização desses conteúdos presentes nos PCNs de Educação Física, por sua vez, se fundamenta na proposta construtivista do psicólogo espanhol César Coll (1996), que foi consultor na elaboração dos PCNs brasileiros. Sinteticamente, sua proposta tem como objetivo a classificação das capacidades do ser humano, para tanto, o teórico apresenta algumas variáveis metodológicas para intervenção nas aulas como, por exemplo, as sequências didáticas para a organização e seleção dos conteúdos, a concepção de aprendizagem dos conteúdos segundo sua tipologia para identificar as intenções educativas, divididas em conteúdos factuais, conceitos e princípios, conteúdos procedimentais e conteúdos atitudinais, além das estratégias de avaliação dos conteúdos. Essas variáveis metodológicas, de acordo com Zabala (1998), teórico espanhol cujos escritos coadunam com as propostas de Coll, têm como objetivo principal a formação de um cidadão integral.

Ó (2011, p. 175) assevera que, a partir da influência do higienismo escolar e do movimento internacional da Educação Nova, o "eco das teses da educação 'integral' do educando" resulta de uma fiscalização, um esquadrinhamento contínuo tanto do corpo e da mente quanto do rendimento escolar e da interação social, que objetivava perscrutar, além das capacidades intelectuais, as "aspirações mais íntimas" dos estudantes.

Silva (2008, p. 256), por sua vez, em um estudo dedicado a análise das metanarrativas educacionais e com base nas concepções pósestruturalistas, contesta os fundamentos das psicologias humanistas e desenvolvimentistas no que diz respeito à propagação da ideia de uma suposta essência humana, que deveria ser desenvolvida em todas as suas potencialidades. Na ótica do autor, as psicologias desenvolvimentistas, ao se fundamentarem em essencialismo e universalismo, "tendem a despolitizar o processo de pensamento, na exata medida em que o concebe fora e acima do contexto político e histórico".

Vários autores levantaram críticas à proposta construtivista que fundamenta os PCNs, produzindo enunciados concorrentes, ainda que não tenham elaborado parametrizações curriculares alternativas. Destaca-se o texto de Moreira (1997), publicado logo após o lançamento dos PCNs, com críticas à teorização curricular psicologizante proposta 
por César Coll, que serviu de base para a elaboração desses parâmetros. Para o autor, os PCNs não levam em conta a complexidade das relações entre educação e sociedade e consistem num modelo atualizado de currículo tradicional, um currículo prescritivo que compreende a qualidade de ensino apenas como a capacidade de aplicação de procedimentos e conteúdos curriculares.

A despeito das críticas e com sua proposta de estabelecer uma base nacional comum, os PCNs, a partir de sua elaboração pelo Ministério da Educação (MEC), foram prontamente divulgados em todo o território nacional, entregues às escolas e aos professores e, por serem elaborados e divulgados em nível nacional, dão a entender que se tratam de documentos obrigatórios (ZANLORENSE; LIMA, 2009).

Com o apoio de Foucault (2008, p. 136), ao se referir às características de uma formação discursiva, especialmente a sua "capacidade de circulação, de troca, [e de] sua possibilidade de transformação [...] na economia dos discursos", podemos pensar que a legitimação do discurso presente nos PCNs se produziu mediante condições de apropriação e utilização por parte dos sujeitos da educação. Desse modo, não é difícil imaginar que as enunciações presentes nesses documentos curriculares funcionem como regra tanto em alguns currículos e livros didáticos dos sistemas de ensino quanto em produções que tratam de temas relacionados à metodologia de ensino e à formação continuada de professores.

Não obstante, ressalte-se, ainda, que, anteriormente à elaboração do currículo de Educação Física de 2008, a referência curricular oficial da disciplina na rede municipal de Sorocaba baseava-se justamente nos PCNs de Educação Física ${ }^{4}$. Assim, a centralidade, e praticamente exclusividade, dada à organização de conteúdos nos currículos de Educação Física de Sorocaba em 2008 e 2010 pode ser associada tanto à circulação dos PCNs nas escolas, como base do planejamento do ensino, como ao enfoque dado a esse arranjo discursivo nas atividades de formação continuada em serviço de professores de Educação Física da rede municipal de Sorocaba, sob a coordenação do IEE.

Conforme mencionado, o IEE inicia suas atividades na rede municipal de Sorocaba no ano de 2006, ofertando um curso de formação em esporte educacional, denominado Programa Método, focado no aprendizado do voleibol, que capacita, inicialmente, 120 professores de Educação Física da rede pública municipal e estadual de Sorocaba. As atividades não se limitaram apenas ao ensino do voleibol, como ocorreu no primeiro ano de atuação, no entanto, a proposta do IEE continuou sendo prioritariamente voltada à aprendizagem de atividades esportivas e de noções de higiene e saúde. 
Nos anos seguintes, capacitaram mais 120 professores e inseriram-se nas atividades pedagógicas de maneira mais ampla, por meio de núcleos esportivos em 20 escolas municipais e estaduais de Sorocaba, além de disseminarem suas concepções teóricas em horários de trabalho pedagógico coletivo dos professores de Educação Física responsáveis pelos núcleos esportivos.

O importante a ressaltar, aqui, é que, ao tomar o discurso curricular como objeto analítico, não temos a pretensão de afirmar que a subjetividade docente seja unicamente produzida no âmbito pedagógico, já que existem inúmeras outras tecnologias discursivas de subjetivação, entretanto, de acordo com algumas investigações (CORAZZA, 2001; LAROSSA, 2008), o discurso curricular constitui em importante lócus para as práticas de subjetivação dos sujeitos da educação.

Diante disso, embora, de fato, não seja possível fazer uma correlação direta entre discurso curricular e processos de subjetivação, vale mencionar o fato de que a organização de conteúdos de aprendizagem fundamenta uma das obras de referência nos momentos de formação continuada na rede de ensino de Sorocaba, intitulada: Práticas pedagógicas reflexivas em esporte educacional, elaborada em 2010 pelos autores Adriano Jose Rossetto Junior, Caio Martins Costa $^{5}$ e Fabio Luiz D’Angelo, coordenadores do IEE e responsáveis pela formação continuada em Sorocaba. Ora, se plausíveis foram os argumentos dos teóricos acima mencionados sobre os processos de subjetivação docente, plausíveis também serão as chances de, em alguma proporção, ter sucedido uma aderência aos discursos em voga no período de formação continuada em serviço.

Voltando à obra empregada na formação continuada em serviço, merece ser ressaltado que, nesse exemplar, os autores se apoiam, entre outros, nas obras dos teóricos espanhóis César Coll (1996) e Antoni Zabala (1998), além dos PCNs de Educação Física (BRASIL, 1997, 1998b, 2000). Vejamos alguns excertos a esse respeito:

Os conteúdos de aprendizagem, de acordo com Coll (1996), são apresentados segundo a sua categoria conceitual (fatos, princípios e conceitos), denotam o aprender a saber; procedimental (habilidades e competências produtivas) ligado a aprender fazer - pesquisar, redigir, construir, jogar, correr, sacar etc. - e atitudinal (normas, valores e atitudes), relacionados ao aprender a ser e conviver, o que permite a identificação mais precisa das intenções educativas, transformando-se nas expectativas de aprendizagem. (ROSSETTO JUNIOR; COSTA; D'ANGELO, 2010, p. 40, grifos dos autores)

A avaliação final permitirá analisar o conjunto de atividades de ensino/ aprendizagem contribui para que cada aluno atingisse os objetivos previstos em determinado grau. Para Zabala (1998), a avaliação final encerra uma unidade 
didática não apenas para mensurar a aprendizagem obtida nas dimensões conceitual, procedimental e atitudinal [...]. (ROSSETTO JUNIOR; COSTA; D’ANGELO, 2010, p. 45, grifos dos autores)

$\mathrm{Na}$ acepção de Rossetto Junior, Costa e D'angelo (2010), as unidades didáticas, que efetivam os ideais traçados no currículo, ou seja, os tipos de atividade e o modo de organizar as aulas, são consideradas imprescindíveis. Nessas unidades didáticas, por sua vez, os conteúdos de aprendizagem são sempre apresentados segundo sua tipologia divididos em conteúdos procedimentais, conceituais e atitudinais - e determinados por faixa etária para o planejamento das aulas.

Pode-se visualizar, portanto, como o enunciado referente à classificação dos conteúdos de aprendizagem em procedimentais, conceituais e atitudinais ocupa espaço privilegiado nos currículos formulados em 2008 e 2010, funcionando como um discurso que produz efeitos de verdade. É importante destacar a presença desse enunciado, oriundo da psicologia educacional (MOREIRA, 1997) e legitimado teoricamente pelos PCNs; um documento tido como obrigatório, que chega aos professores sob as mais variadas formas, isto é, são incorporados e propagados por outras instâncias enunciativas, como documentos curriculares, livros didáticos, revistas pedagógicas, conteúdo curricular de cursos de licenciatura, entre outros.

\section{A ORGANIZAC̣ÃO CURRICULAR POR COMPETÊNCIAS SOB O CONTROLE DA GESTÃO CURRICULAR}

Nesta seção, investigamos as competências como princípio de organização curricular. Tal discurso tem assumido um papel central nas últimas décadas e parece ser a mais nova palavra de ordem na educação brasileira, fundamentando uma série de documentos de âmbito federal e estadual (MACEDO, 2002). Conforme anunciado, a organização curricular por competências alicerça o documento curricular oficial da rede municipal de Sorocaba.

\footnotetext{
No presente trabalho todo o currículo está organizado tomando como referência as competências/habilidades ou expectativas de aprendizagem e os conteúdos a serem trabalhados para que essas expectativas se concretizem em direitos de aprendizagem assegurados aos alunos. Em todas as disciplinas se apresenta uma matriz com duas colunas: uma de conteúdos e outra de competências em forma de habilidades mais específica porque associada a apenas alguns tópicos de conteúdo. (SOROCABA, 2012, p. 20)
}

O currículo de Educação Física examinado destaca que a utilização das competências na organização curricular se dá porque 
“constituem até agora a melhor resposta que a pedagogia e a didática podem dar para as necessidades de aprendizagem colocadas pela sociedade do conhecimento que emergiu da revolução tecnológica" (SOROCABA, 2012, p. 22). Passa-se a impressão de que basta utilizar essa concepção para a garantia do aprendizado, em associação ao discurso de que as novas opções são sempre melhores que as anteriores, especialmente se forem apresentadas como inovações tecnológicas. Esse enunciado remete à formulação de Gregolin (2004) a respeito das relações possíveis do enunciado com tempos passados e futuros, isto é, se a noção de competências até o momento é o que há de melhor para a garantia de aprendizagem, possivelmente continuará habitando os currículos futuramente.

Apesar do aparente prestígio que a organização curricular por competências parece dispor, levando à compreensão de que bastaria seguir as prescrições de tal modelo para o sucesso de aprendizagem dos estudantes, o enunciado "só pode ser apanhado em uma trama complexa de produção de sentidos" (GREGOLIN, 2004, p. 30). Desse modo, fazer alusão ao enunciado referente à organização curricular por competências requer, inicialmente, compreender sua polissemia de sentidos, decorrente do fato de que diferentes vertentes teóricas a fundamentam.

A esse respeito, Dias e Lopes (2003) esclarecem que, apesar do discurso sobre competências ter ganhado força a partir da década de 1990 no Brasil, se trata de uma recontextualização, já que esse conceito de competências teria sido utilizado em épocas anteriores, mais especificamente, nas décadas de 1960 e 1970 em programas brasileiros e americanos de formação de professores. Para as autoras, esse discurso partia da ideia de que um aluno com bom desempenho possuía um bom professor, ou melhor, um professor eficiente. Desse modo, surgiram, na década de 1960 nos Estados Unidos, diversos programas de formação do professor baseada em competências (Competency-Based TeacherEducation-CBTE) e de educação do professor baseada em desempenho (Performance-Based TeacherEducation-PBTE). Esses programas definiam uma listagem de competências necessárias ao professor e acabaram influenciando a noção de profissionalização do trabalho docente, porém, desconsiderando a especificidade e a própria história da profissão docente.

Esse significado da noção de competências mencionado acima é proveniente da abordagem comportamental de tradição americana, que se inicia com as teorias de eficiência social desenvolvidas por Franklin Bobbitt, Ralph Tyler e Werret Charters e que, posteriormente, influenciaram teóricos como Robert Mager,James Popham e Benjamin 
Bloom. Este último, com o apoio de alguns colaboradores, publica, em 1956, a obra intitulada: Taxonomia de objetivos educacionais, que serviu como importante referência para outros estudos. Grosso modo, os autores criaram uma divisão de objetivos educacionais nos domínios cognitivo (conhecimentos e habilidades mentais), afetivo (atitudes, valores e interesses) e psicomotor (habilidade motora, destreza manual e coordenação neuromuscular) (PACHECO, 2001).

No entanto, em estudos posteriores, ocorrem convergências conceituais nessa divisão de objetivos educacionais propostos pelos eficientistas sociais. Recentemente, os estudos desenvolvidos pelos teóricos espanhóis Coll (1996) e Zabala (1998), cujos escritos se enquadram nas concepções construtivistas-cognitivistas, têm tentado ampliar a forma de classificar as capacidades humanas, oriundas da abordagem comportamental de Benjamin Bloom e colaboradores (MOGILKA, 2012).

Um dos atuais significados das competências como tecnologia de organização curricular remete à ideia de integração curricular. Macedo (2002) cita como exemplo as Diretrizes para a formação de professores, em que a perspectiva de formação não segue uma lógica disciplinar ao tomar como referência um conjunto de competências genéricas consideradas necessárias à formação dos professores.

No documento curricular de Educação Física investigado, a noção de integração curricular é um dos raciocínios utilizados para justificar a adoção da organização curricular por competências:

A característica fundamental do currículo organizado por competências é que a responsabilidade pelo desenvolvimento das mesmas é de todas as áreas ou disciplinas do currículo. São as competências para aprender e continuar aprendendo. Isso explica em parte a adoção generalizada da organização curricular por competências nos sistemas educacionais contemporâneos. As competências são marcadores transversais que, sem ser aderentes a conteúdos curriculares específicos, são responsabilidade de todos eles porque essenciais para aprender todo e qualquer conteúdo. (SOROCABA, 2012, p. 22)

Essa lógica é associada às ideias de transdisciplinaridade e interdisciplinaridade, isto é, tem procurado atender às questões sobre organização dos conhecimentos sem recorrer explicitamente às disciplinas escolares. De acordo com Macedo (2002), a noção de integração curricular refere-se a um dos discursos que mais constituem consenso da comunidade escolar, por ser compreendido, inicialmente, como um discurso crítico. Citando o caso dos PCNs do Ensino Médio, que assumem esse sentido interdisciplinar, ela adverte que tal incorporação não se deu sem processos de hibridização discursiva. 
Como explica Lopes (2008), outro significado do currículo por competências se baseia em uma articulação entre competência e desempenho, que denomina de saber fazer. Esse entendimento de currículo por competências associado ao desempenho também é uma das concepções utilizadas para a validação do enunciado no currículo de 2012. Vejamos como isso se dá: "a competência refere-se a um processo interno, uma operação mental e afetiva, uma mobilização de experiências anteriores, que resulta num saber fazer novo e bemsucedido" (SOROCABA, 2012, p. 21).

Nesse raciocínio, o enunciado indica que a competência deve ser demonstrada em ações práticas e eficientes, reportando às teorias de eficiência social, que possuem um caráter instrumental, isto é, uma incisiva ligação entre o currículo e os processos de produção, transformando o processo educacional em uma lógica associada aos ditames do mercado de trabalho. Não por acaso, uma das competências requeridas aos alunos no currículo investigado se refere à capacidade de "aprender a empreender" (SOROCABA, 2012, p. 19).

Ainda em referência à organização desse enunciado, é possível visualizar aproximações à vertente cognitivista-piagetiana, ao considerar a competência como um processo de desenvolvimento cognitivo interno. Adentremos a questão:

Há uma dimensão de grande importância no uso de competências ou expectativas de aprendizagem como referência do currículo: o conceito se refere sempre, sem exceção, a processos que devem ocorrer internamente no aluno, a mudanças que devem se operar nas estruturas mentais ou afetivas, nos hábitos culturais e sociais, e que se manifestam num saber ou num proceder ou num saber fazer novos. (SOROCABA, 2012, p. 18)

Para validar esse uso do conceito de competência vale a pena recorrer ao Marco Referencial ${ }^{8}$, que o valida quando, às páginas 95 e 96, afirma, referindo-se a Piaget: ' $\mathrm{O}$ processo de assimilação se refere à tentativa feita pelo sujeito de solucionar uma nova situação utilizando uma estrutura mental já formada'. (SOROCABA, 2012, p. 21)

O primeiro excerto assume a posição de que as competências funcionam como solução ou dimensão de grande importância para garantia de determinados saberes assimilados pelos alunos. Além disso, busca cristalizar o sentido de competências, afirmando que "se refere sempre, sem exceção, a processos que devem ocorrer internamente no aluno". Já o segundo excerto se vale do aval de uma autoridade na área, aparentemente com o intuito de credibilizar o conceito de competências no documento curricular. Como ensina Foucault em sua aula inaugural, pronunciada em 1970 no Collège de France, alguns discursos são impenetráveis para os desqualificados: “[...] ninguém 
entrará na ordem do discurso se não satisfizer a certas exigências ou se não for, de início, qualificado para fazê-lo. Mais precisamente: nem todas as regiões do discurso são igualmente abertas e penetráveis; algumas são altamente proibidas [...]" (FOUCAULT, 1996, p. 37).

Em associação à necessidade de produzir competências em alunos e professores, o documento curricular indica a importância da chamada gestão curricular, para garantir que os conteúdos e as estratégias de ensino presentes no documento sejam efetivamente colocados em ação pelos docentes e que essas competências sejam implementadas.

Os objetivos presentes na concepção de gestão curricular parecem próximos àqueles da noção de gestão educacional, conforme apresentaremos nas linhas a seguir. O estudo genealógico de Klaus et al. (2015) indica que a gestão educacional irrompe em meados da década de 1990, a partir da mudança de ênfase de uma concepção anterior de administração educacional para uma concepção de gestão educacional que, apesar de descontinuidades, apresenta o mesmo fio condutor: a utilização de estratégias educacionais com o intuito de governamento dos sujeitos da educação.

A justificativa oferecida para a gestão curricular no impresso examinado aponta o fato de que os sistemas de ensino demoraram algum tempo para perceber que tanto os PCNs quanto as Diretrizes Curriculares Nacionais não servem como um guia prático, de maneira que, entre as proposições teóricas desses documentos e a prática pedagógica em sala de aula, "há um vácuo que só pode ser preenchido com a gestão curricular" (SOROCABA, 2012, p. 8). Essa atividade seria ampla, abarcando as várias perspectivas da atividade escolar, como detalhado no documento curricular:

Fazer a gestão do currículo é promover, apoiar e supervisionar a integração e o alinhamento, sob uma concepção educacional, as aprendizagens com as quais a escola se compromete na forma de aprendizagens a serem constituídas pelos alunos, de acordo com seus interesses e características pessoais; as propostas de metodologias, estratégias, projetos de ensino, situações de aprendizagem; os recursos didáticos com os quais a escola conta, incluindo instalações que viabilizam, estas por sua vez incluindo a acessibilidade arquitetônica e ou pedagógica para todos os alunos, equipamentos, materiais de apoio adaptados às necessidades individuais de alunos e professores; as propostas de educação continuada dos professores; a concepção e o formato da avaliação. (SOROCABA, 2012, p. 10)

Embora haja diversas citações nesse documento referindo-se à gestão curricular, não fica claro quem de fato seria o responsável por essa gestão. O alvo dessa gestão, no entanto, é explicitado claramente como sendo o professor: 
É fato exaustivamente documentado em pesquisas que os determinantes mais poderosos do desempenho dos alunos estão fora do controle da escola, na origem familiar. No entanto é também constatado empiricamente que, entre aqueles determinantes sobre os quais a escola tem poder de decisão, o de maior peso individual é o professor e a qualidade da sua mediação pedagógica com os seus alunos e a sua sala de aula. Todos os demais são residuais. Por essa razão o principal objeto da gestão curricular é o professor, sua prática, apoio técnico e de infraestrutura, e principalmente formação em serviço. O gestor do currículo é, em última instância, e antes de tudo, um formador e mediador das necessidades de aprendizagem de professores em serviço, colocando em ação um currículo de formação. A redundância é apenas aparente, pois o currículo da educação básica que o professor coloca em ação, deve ser também referência para o currículo que orienta a formação em serviço. (SOROCABA, 2012, p. 11)

A gestão curricular se coloca como uma tentativa de eliminar o que seria uma lacuna entre os discursos e as práticas. Em outras palavras, busca investir em estratégias de um minucioso controle da ação docente para que o conhecido dito popular "na prática, a teoria é outra" não se aplique ao desenho curricular proposto para a rede municipal de Sorocaba.

As enunciações do documento curricular implicam na desqualificação dos professores quando abordam supostos problemas em sua formação inicial, considerada fragmentada, generalista e academicista: "a formação dos professores dos anos finais do ensino fundamental e do ensino médio está fincada na divisão disciplinar do ensino superior" (SOROCABA, 2012, p. 18).

A formação dos professores do Ensino Infantile das séries iniciais do Ensino Fundamental, por sua vez, é considerada "congestionada de conhecimentos pedagógicos sem considerar o domínio sólido dos conteúdos a serem ensinados e, consequentemente, as necessárias intervenções didáticas para ensiná-los" (SOROCABA, 2012, p. 18).

A proposta curricular em análise opta por iniciar suas considerações mediante materiais dedicados aos professores, pois "quem ensina é quem mais precisa aprender" (SOROCABA, 2012, p. 17). Considerando a flagrante vulnerabilidade intelectual docente que é enunciada nos excertos selecionados, acredita-se que somente a aderência da formação continuada às práticas indicadas no documento curricular pode representar a superação desses problemas.

O discurso da incompetência dos professores, bem como a sua crítica não são criações recentes, vêm sendo produzidos e atualizados há décadas. Souza (2006) pondera que o argumento da incompetência docente, bastante popular na academia e no sistema escolar, é utilizado para apoiar a crescente importância de programas de formação continuada, de forma a preencher lacunas na formação inicial dos educadores. Para a autora, essa concepção deve-se a uma mudança de 
foco em produções da psicologia escolar de teor medicalizante, que atribuía o problema do fracasso escolar aos alunos e suas famílias, em direção a uma visão em que a instituição escolar é responsabilizada por tal problema, especialmente o professor e suas práticas pedagógicas. Esse processo acaba reforçando a ideia de incompetência docente e, indevidamente, confere, às propostas formativas, o poder de superar o fracasso escolar e melhorar a qualidade do ensino.

No presente estudo, identificamos a permanência do discurso da incompetência e da necessidade de formação continuada, em associação, neste caso, com a necessidade de cumprir as propostas curriculares, mediante ações de gestão curricular. Há uma desconfiança na formação dos professores e parte-se da ideia de que todos apresentam falhas em sua formação inicial, alguns por possuírem uma formação generalista insuficiente, outros por receberem formação específica, igualmente insatisfatória. A necessidade de gestão e formação curricular, por meio da educação continuada, surge com a incumbência de sanar essas falhas de formação dos professores, considerados desatualizados, treinando-os de modo que coloquem em ação uma determinada maneira de exercer a docência, de acordo com as proposições do currículo.

Ao mencionar como objetivo principal a formação e a mediação das necessidades de aprendizagem de professores em serviço, a gestão curricular se coloca como um dispositivo de vigilância, com a intenção de "estruturar o eventual campo de ação dos outros" (FOUCAULT, 1995, p. 244), produzindo uma ação controladora sobre o uso dos pressupostos curriculares da rede municipal de Sorocaba, haja vista que o intuito é que o currículo escrito se aproxime ao máximo do currículo em ação, via atividades formativas promovidas pela gestão curricular.

Nessa modalidade de governamentalidade, que intenta normalizar, controlar e programar as condutas, com vistas a um suposto bem comum educativo, urge que os docentes se mantenham sempre atualizados, por meio de um conjunto de ações programadas que, acredita-se, garantirá o aumento da eficiência e produtividade. Trata-se, portanto, de uma discursividade que incita a um investimento permanente, em consonância aos imperativos de uma cultura empreendedora que adentra, cada vez mais, no âmbito educacional (GADELHA COSTA, 2009). Em última instância, desenvolvimento de competências, habilidades e aptidões são palavras de ordem direcionadas não somente aos discentes, mas a todos os sujeitos da educação.

Acreditamos, portanto, que o modo de enunciação da gestão curricular ocorre em associação a uma desvalorização da experiência 
docente e a um esvaziamento da ação educativa, tendo em vista que esta se resume no acautelado implemento das prescrições curriculares, via tutoria tecnocrática.

\section{CAMPO DE COEXISTÊNCIAS EM ENUNCIADOS DOS DOCUMENTOS CURRICULARES}

Nesta seção, com base nas noções de enunciado e formação discursiva desenvolvidas por Michel Foucault (2008) em $A$ arqueologia do saber, analisamos o campo de coexistências a respeito de algumas "coisas ditas" nos documentos curriculares, isto é, identificamos relações entre determinados enunciados que constituem os documentos curriculares de Educação Física investigados, buscando associá-los a determinada formação discursiva.

Mais especificamente, intentamos apontar o campo de coexistências dos enunciados referentes à organização curricular por competências e em conteúdos de aprendizagem nas dimensões procedimentais, conceituais e atitudinais.

Apesar de os currículos de 2008 e 2010 se dedicarem quase que exclusivamente a um quadro de organização de conteúdos de aprendizagem, é possível estabelecer um campo de coexistências com enunciados do currículo oficial elaborado em 2012. Ainda que não haja uma relação intertextual direta, a função enunciativa aparenta derivar das mesmas regras de formação discursiva - o discurso da psicologia educacional. A respeito de enunciados distintos, mas que obedecem à mesma finalidade, Gaspar (2004) aponta:

Em todo o Capitulo III da Arqueologia do saber, denominado O Enunciado e o Arquivo, Foucault oferece vários exemplos de enunciados que contém formas materiais distintas, mas que cumprem a mesma função ou que poderiam ser percebidos com os mesmos conteúdos informativos e as mesmas possibilidades de utilização na análise. (GASPAR, 2004, p. 257, grifos da autora)

Com o apoio dos escritos foucaultianos, é possível pensar que uma formação discursiva está vinculada a determinado campo de saber, desse modo, quando se fala em discurso da psicologia educacional, se compreende um conjunto de enunciados, baseados em uma formação discursiva específica, o que não significa o entendimento de que a formação discursiva da psicologia educacional ou qualquer outra formação discursiva seja um sistema fechado, com uma fronteira estritamente delimitada, já que os enunciados podem ser tangenciados por formações discursivas distintas (FOUCAULT, 2008).

Dito de outro modo, o discurso da psicologia educacional tem suas margens compostas por vários enunciados e sentidos que 
se deslocam, resultado de práticas discursivas diversas. Para apoiar esse raciocínio, recorremos às assertivas de Moreira (1997) que, discorrendo sobre os fundamentos teóricos que subsidiam o desenho curricular proposto por Coll e tomados como base na elaboração dos PCNs, identifica uma supervalorização da psicologia educacional. Ainda assim, mesmo que de modo secundário e a partir de discussões superficiais, aponta também fontes oriundas da sociologia, da epistemologia e da prática pedagógica.

Com o apoio de Ó (2011), é possível visualizar como a ciência psicopedagógica é uma forma de saber presente no campo educacional desde os fins do século XIX:

Toda a relação educativa moderna tem uma raiz 'psi', o que significa que passou a depender de diagnósticos, orientações teóricas, divisões e formas de explicação que a Psicologia concebeu para indexar e reelaborar os imperativos éticos. Podemos então falar de uma regulação psicológica do eu como derivada daquela ciência da alma em franca expansão há mais de um século. Apontando para as capacidades e aptidões, saúde e doenças, virtudes e perversões, normalidade e patologias do escolar, a Psicologia está na base, de fato, de todas as técnicas e dispositivos relativos à identidade e à conduta. (Ó, 2011, p. 179)

Constatada essa dispersão e heterogeneidade dos enunciados, o que poderia caracterizar os enunciados como pertencentes à mesma formação discursiva? Para explicar tal especificação, Foucault (2008, p. 166) se vale da metáfora da árvore, em cujos tronco e raízes estariam "os enunciados que empregam as regras de formação em sua extensão mais ampla"; e nos galhos e folhas se encontrariam "os enunciados que empregam a mesma regularidade, porém mais sutilmente articulada, mais bem delimitada e localizada em sua extensão".

A partir desse entendimento, é possível visualizar uma relação, um encadeamento entre os enunciados referentes à organização curricular nos documentos investigados a partir das regras de formação mais ampla, isto é, ambos enunciados buscam suporte nas bases científicas da psicologia educacional como, por exemplo, na retórica alusiva à aprendizagem como um processo cognitivo interno, ou seja, a ideia de que cada pessoa constrói seu próprio conhecimento, que se dá por meio da associação linear de esquemas mentais prévios e característicos do ser humano, além da valorização e projeção de um sujeito integral, autônomo e eficiente.

Para Dreyfus e Rabinow (1995), embora as políticas disciplinares de poder não se situem em instituições particulares, quando encontram uma localização em instituições específicas como, por exemplo, o sistema de ensino, se tornam eficazes. Nas políticas curriculares brasileiras - e esse parece ser também o caso da política curricular da Secretaria da 
Educação de Sorocaba -, essa eficácia pode ser atribuída à função enunciativa da psicologia educacional, que, como apontam diversos autores (Ó, 2011; CORAZZA, 1995; GORE, 2008; MOREIRA, 1997; AQUINO; RIBEIRO, 2009), ao ser sancionada por um cientificismo, exerce ampla influência no discurso curricular contemporâneo.

Em seu célebre texto intitulado Inventando nossos eus, Rose (2001) sustenta a ideia de que os saberes psicologizantes extrapolam a esfera educacional e são incorporados por uma multiplicidade de instâncias sociais, cujos agenciamentos contemporâneos constituem em importante lócus de subjetivação. Vejamos um fragmento a esse respeito: "Os saberes e as autoridades psi têm gerado técnicas para moldar e reformar os eus, as quais têm sido reunidas - em um agenciamento - com os aparatos dos exércitos, das prisões, das salas de aula, dos quartos de dormir, das clínicas..." (ROSE, 2001, p. 147).

Conformejá mencionado, as propostas de currículos que adotam enunciados psicologizantes ganham força no Brasil por meio de um conjunto de formulações e processos de institucionalização via sistema educacional por volta da década de 1990, época em que disseminam documentos oficiais, como é o caso, por exemplo, dos PCNs, das Diretrizes Curriculares para o Ensino Fundamental, das Matrizes Curriculares de Referência para o Sistema de Avaliação da Educação Básica e das Diretrizes Curriculares para a Formação de Professores de Educação Básica. Além desses documentos de âmbito federal, temos ainda documentos curriculares de nível estadual e municipal, como o currículo da rede estadual de São Paulo e os documentos curriculares da Secretaria da Educação de Sorocaba. Destacamos abaixo passagens de alguns desses documentos supracitados:

Nos Parâmetros Curriculares Nacionais, os conteúdos referentes a conceitos, procedimentos, valores, normas e atitudes estão presentes nos documentos tanto de Áreas quanto de Temas Transversais, por contribuírem para a aquisição das capacidades definidas nos Objetivos Gerais do Ensino Fundamental. (BRASIL, 1998a, p. 79)

A partir desses princípios gerais, o currículo deve ser articulado em torno de eixos básicos orientadores da seleção de conteúdos significativos, tendo em vista as competências e habilidades que se pretende desenvolver no Ensino Médio. (BRASIL, 2000, p. 16)

Um currículo que promove competências tem o compromisso de articular as disciplinas e as atividades escolares com aquilo que se espera que os alunos aprendam ao longo dos anos [...] Com efeito, um currículo referenciado em competências supõe que se aceite o desafio de promover os conhecimentos próprios de cada disciplina articuladamente às competências e habilidades do aluno. (SÃO PAULO, 2010, p. 9) 
O discurso da psicologia educacional tem suas margens povoadas por uma série de enunciados heterogêneos, resultado de práticas discursivas diversas, mas também enunciados que se apoiam, se legitimam mutuamente e se atravessam, como é o caso, por exemplo, dos PCNs que adotam a tipologia de conteúdos de aprendizagem para o Ensino Fundamental e a organização curricular por competências para o Ensino Médio. Além dos PCNs, também se enquadram, nessa perspectiva, os currículos da rede municipal de Sorocaba aqui investigados, cujos enunciados se referem ora à organização de conteúdos de aprendizagem nas dimensões procedimentais, conceituais e atitudinais, ora ao ensino baseado em competências ou, ainda, incorporando os dois enunciados, indicando, assim, um campo de coexistências. Um excerto do impresso curricular de 2012 é revelador nesse sentido:

A Proposta Curricular da educação municipal de Sorocaba adota o termo 'competências' a serem constituídas nos alunos, em quase todas as disciplinas. Além disso, adota também a classificação dos conteúdos curriculares em cognitivos, procedimentais e atitudinais seguindo o modelo dos PCNs para o ensino fundamental. (SOROCABA, 2012, p. 19)

Essa forma de coexistência, por sua vez, delineia um campo de presença, que reúne enunciados admitidos como verdadeiros. Desnecessário, talvez, a esta altura, apontarmos que, nos impressos aqui perscrutados, trata-se precisamente de enunciados oriundos da formação discursiva da psicologia educacional e sua abordagem nitidamente instrumental.

\section{CONSIDERACְ̃̃ES FINAIS}

Após esse percurso de pensamento, algumas considerações podem ser apontadas a respeito do predomínio da organização curricular fundamentada na psicologia educacional nas produções curriculares da rede de ensino municipal de Sorocaba.

A primeira delas é que a recorrência do modelo de organização curricular com base nos conteúdos de aprendizagem conceitual, procedimental e atitudinal - que alicerça os currículos de 2008 e 2010 - não ocorre por acaso, tendo em vista que este opera em diversas instâncias enunciativas, entre elas os PCNs de Educação Física, compreendido como um documento obrigatório e que funciona como um dispositivo que produz efeitos de verdade, devido a sua propagação e aceitação no contexto educacional brasileiro. Além disso, destacamos a formação continuada em serviço dos professores de Educação Física, fundamentada nos parâmetros de ordenamento curricular em questão. 
A evocação constante à organização curricular por competências no documento curricular de 2012 aponta que este é um conceito-chave para a produção e dispersão de práticas discursivas no âmbito educacional - local privilegiado para a materialidade do enunciado; afinal, podem remeter, conforme mostramos, à psicologia comportamental e cognitivista. Constatamos também que a regularidade das competências enquanto princípio de organização curricular está associada à atribuição de uma ação prática de cada conhecimento.

Dessa maneira, as competências devem ser traduzidas em ações e comportamentos observáveis e, portanto, evidenciam um caráter instrumental, insistindo em um raciocínio que associa o conhecimento ao pragmatismo, resultando em uma lógica reducionista da função da educação escolar. Merece ser destacado ainda que esse enunciado, validado pelo discurso proveniente do pensamento construtivista-cognitivista piagetiano, associado à tradição francesa de organização curricular, é tomado como uma das prescrições nucleares de organização no currículo de 2012, mais precisamente, é entendido como a melhor resposta para as necessidades de aprendizagem atuais, contudo, não há qualquer menção sobre quais seriam efetivamente as tão propagadas necessidades de aprendizagem enunciadas no currículo e a quem de fato beneficiaria.

Concluímos que a educação continuada como estratégia de gestão curricular visa um esquadrinhamento sistemático dos comportamentos dos professores, para que se autogovernem e a gestão curricular se torne cada vez mais eficiente e econômica. Ainda, o enunciado referente à gestão curricular sugere que os sujeitos da educação reconheçam a si mesmos, independentemente de formação generalista ou específica, como desatualizados, levandoos a encontrar, no fiel cumprimento das prescrições curriculares, a resolução para suas deficiências.

Por fim, embora não haja uma relação intertextual direta, é possível visualizar um campo de coexistências entre a tipologia de conteúdos de aprendizagem e organização curricular por competências, ambos enunciados associados à formação discursiva da psicologia educacional. À vista disso, podemos dizer que a disseminação dos enunciados, aqui em análise, nos três documentos curriculares investigados, ligados à formação discursiva da psicologia educacional e presentes em diversos documentos curriculares contemporâneos, demonstra sua positividade, sua repercussão e parece alcançar uma condição estável e a possibilidade de aceitação no cenário educacional, possivelmente resultado do respaldo científico e da ampla divulgação. 


\section{REFERÊNCIAS}

AQUINO, Julio Groppa; RIBEIRO, Cintya. Processos de governamentalização e a atualidade educacional: a liberdade como eixo problematizador. Educação \& Realidade, Porto Alegre, v. 34, n. 2. p. 57-72, maio/ago. 2009.

BRASIL. Ministério da Educação. Secretaria de Educação Fundamental. Parâmetros Curriculares Nacionais primeiro e segundo ciclos do Ensino Fundamental: Educação Física. Brasília: MEC/SEF, 1997.

BRASIL. Ministério da Educação. Secretaria de Educação Fundamental. Parâmetros Curriculares Nacionais terceiro e quarto ciclos do Ensino Fundamental: introdução aos parâmetros curriculares nacionais. Brasília: MEC/SEF, 1998a.

BRASIL. Ministério da Educação. Secretaria de Educação Fundamental. Parâmetros Curriculares Nacionais terceiro e quarto ciclos do Ensino Fundamental: Educação Física. Brasília: MEC/SEF, 1998b.

BRASIL. Ministério da Educação. Secretaria de Educação Média e Tecnológica. Parâmetros Curriculares Nacionais: Ensino Médio. Brasília: MEC/SEF, 2000.

CANDIOTTO, Cesar. Foucault e a crítica da verdade. 2. ed. Belo Horizonte: Champagnat, 2013.

COLL, Cesar. Psicologia e currículo. São Paulo: Ática, 1996.

COLL, Cesar et al. Psicologia do ensino. Porto Alegre: Artmed, 2000.

CORAZZA, Sandra Mara. O construtivismo pedagógico como significado transcendental do currículo. In: VEIGA-NETO, Alfredo et al. (Org.). Crítica pós-estruturalista e educação. Porto Alegre: Sulina, 1995.

CORAZZA, Sandra Mara. O que quer um currículo?: pesquisas pós-críticas em educação. Petrópolis-RJ: Vozes, 2001.

DIAS, Rosanne Evangelista; LOPES, Alice Casimiro. Competências na formação de professores: o que (não) há de novo. Educação e Sociedade, Campinas, v. 24, n. 85, p. 1155-1177, dez. 2003. Disponível em: <http://www.scielo.br/pdf/es/v24n85/a04v2485. pdf>. Acesso em: 29 nov. 2013.

DREYFUS, Hubert; RABINOW, Paul. Michel Foucault, uma trajetória filosófica: para além do estruturalismo e da hermenêutica. Rio de Janeiro: Forense Universitária, 1995.

DUSSEL, Inés. O currículo híbrido: domesticação ou pluralização das diferenças? In: LOPES, Alice Casimiro; MACEDO, Elizabeth. (Org.). Currículo: debates contemporâneos. São Paulo: Cortez, 2002. p. 55-77.

FISCHER, R. M. B. 1996. 297 f. Adolescência em discurso: mídia e produção de subjetividade. Tese (Doutorado em Educação) - Faculdade de Educação da Universidade Federal do Rio Grande do Sul, Porto Alegre - RS, 1996.

FOUCAULT, Michel. O sujeito e o poder. In: DREYFUS, Hubert. L.; RABINOW, Paul. Michel Foucault, uma trajetória filosófica: para além do estruturalismo e da hermenêutica. Rio de Janeiro: Forense Universitária, 1995. p. 231-239.

FOUCAULT, Michel. A ordem do discurso. 3. ed. São Paulo: Loyola, 1996.

FOUCAULT, Michel. A arqueologia do saber. 3. ed. Rio de Janeiro: Forense Universitária, 2008.

GADELHA COSTA, Sylvio. Governamentalidade neoliberal, teoria do capital humano e empreendedorismo. Educação e Realidade, Porto Alegre, v. 34, n. 2, p. 171-186, maio/ ago. 2009. Disponível em: <http://seer.ufrgs.br/index.php/educacaoerealidade/article/ view/8299/5537>. Acesso em: 7 jun. 2013. 
GASPAR, Nádea Regina. Foucault nas visibilidades enunciativas. In: SARGENTINI, Vanice; NAVARRO-BARBOSA, Pedro. (Org.). Foucault e os domínios da linguagem: discurso, poder, subjetividade. São Carlos: Claraluz, 2004. p. 231-259.

GORE, Jennifer. Foucault e a educação: fascinantes desafios. In: SILVA, Tomaz Tadeu da. O sujeito da educação: estudos foucaultianos. 6. ed. Petrópolis: Vozes, 2008. p. 9-20.

GREGOLIN, Maria do Rosário. O enunciado e o arquivo: Foucault (entre)vistas. In: SARGENTINI, Vanice; NAVARRO-BARBOSA, Pedro. (Org.). Foucault e os domínios da linguagem: discurso, poder, subjetividade. São Carlos: Claraluz, 2004. p. 23-44.

KLAUS, Viviane et al. Genealogia foucaultiana e políticas educacionais: possibilidades analíticas. Perspectivas, Florianópolis, v. 33, n. 2, p. 665-687, maio/ago. 2015. Disponível em: <https:// periodicos.ufsc.br/index.php/perspectiva/article/view/35488>. Acesso em: 07 nov. 2016.

LARROSA, Jorge. Tecnologias do eu e educação. In: SILVA, Tomaz Tadeu da. (Org.). O sujeito da educação: estudos foucaultianos. 6. ed. Petrópolis: Vozes, 2008. p. 35-86.

LOPES, Alice Casimiro; MACEDO, Elizabeth. O pensamento curricular no Brasil. In: LOPES, Alice Casimiro; MACEDO, Elizabeth (Org.). Currículo: debates contemporâneos. São Paulo: Cortez, 2002. p. 13-54.

LOPES, Alice Casimiro. Políticas de integração curricular. Rio de Janeiro: EdUERJ, 2008.

MACEDO, Elizabeth. Currículo e competência. In: LOPES, Alice Casimiro; MACEDO, Elizabeth. (Org.). Disciplinas e integração curricular: história e políticas. Rio de Janeiro: DP\&A, 2002. p. 115-144.

MOGILKA, Maurício. Infância e formação integral. Educere et Educare, Cascavel, v. 7, n. 14, p. 12-20, jul./dez. 2012. Disponível em: < http://e-revista.unioeste.br/index.php/ educereeteducare/article/view/7072/6640>. Acesso em: 19 dez. 2013.

MOREIRA, Antônio Flavio Barbosa. A psicologia... e o resto: o currículo segundo César Coll. Cadernos de Pesquisa, São Paulo, n. 100, p. 93-107, mar. 1997. Disponível em: < http:// www.fcc.org.br/pesquisa/publicacoes/cp/arquivos/325.pdf>. Acesso em: 19 jul. 2013.

NAVARRO-BARBOSA, Pedro. O acontecimento discursivo e a construção da identidade na história. In: SARGENTINI, Vanice; NAVARRO-BARBOSA, Pedro. (Org.). Foucault e os domínios da linguagem: discurso, poder, subjetividade. São Carlos: Claraluz, 2004. p. 97-130.

NEIRA, Marcos Garcia; NUNES, Mário Luiz Ferrari. Educação Física, currículo e cultura. São Paulo: Phorte, 2009.

Ó, Jorge Ramos do. Tecnologias de subjetivação no processo de transformação da criança em aluno a partir dos finais do século XIX. In: CASTELO BRANCO, Guilherme; VEIGANETO, Alfredo. (Org.). Foucault: filosofia \& política. Belo Horizonte: Autêntica Editora, 2011. p. 175-194.

PACHECO, José. Competências curriculares: as práticas ocultas nos discursos da reforma. In: REUNIÃO ANUAL DA ANPED, 24., 2001, Caxambu. Anais... Caxambu: ANPEd, 2001. Disponível em: <http://www.anped.org.br/reunioes/24/ts2.doc.>. Acesso em: 17 dez. 2013. ROSE, Nikolas. Inventando nossos eus. In: SILVA, Tomaz Tadeu da. (Org.). Nunca fomos humanos. Belo Horizonte: Autêntica, 2001. p. 137-204.

ROSSETTO JUNIOR, Adriano José; COSTA, Caio Martins; D’ANGELO, Fabio Luiz. Práticas pedagógicas reflexivas em esporte educacional: unidade didática como instrumento de ensino e aprendizagem. São Paulo: Phorte Editora, 2010.

SÃO PAULO (Estado). Secretaria da Educação. Currículo do estado de São Paulo: linguagens, códigos e suas tecnologias. São Paulo: SEE, 2010. 
SILVA, Tomaz Tadeu da. O adeus as metanarrativas educacionais. In: SILVA, Tomaz Tadeu da (Org.). O sujeito da educação: estudos foucaultianos. 6. ed. Petrópolis: Vozes, 2008. p. 247-258.

SILVA, Tomaz Tadeu da. Documentos de identidade: uma introdução às teorias do currículo. 3. ed. Belo Horizonte: Autêntica, 2011a.

SILVA, Tomaz Tadeu da. Currículo e identidade social: territórios contestados. In: SILVA, Tomaz Tadeu da (Org.). Alienígenas na sala de aula: uma introdução aos estudos culturais em educação. 9. ed. Petrópolis: Vozes, 2011b. p. 185-202.

SOROCABA. Secretaria de Educação. Currículo mínimo de Educação Física. Sorocaba: Secretaria de Educação, 2008.

SOROCABA. Secretaria de Educação. Currículo mínimo de Educação Física. Sorocaba: Secretaria de Educação, 2010.

SOROCABA. Secretaria de Educação. Matriz curricular de Educação Física. Sorocaba: Instituto Paradigma, 2012.

SOUZA, Denise Trento Rebello. Formação continuada de professores e fracasso escolar: problematizando o argumento da incompetência. Educação e Pesquisa, São Paulo, v. 32, n. 3, p. 477-492, set./dez. 2006.

ZABALA, Antoni. A prática educativa: como ensinar. Porto Alegre: Artmed, 1998.

ZANLORENSE, Maria Joselita; LIMA, Michelle Fernandes. Uma análise histórica sobre a elaboração e divulgação dos PCN no Brasil. In: HISTEDBR SEMINÁRIO NACIONAL DE ESTUDOS E PESQUISAS: HISTÓRIA, SOCIEDADE E EDUCAÇÃO, 8., 2009, Campinas. Anais... Campinas: HISTEDBR, 2009. Disponível em: < http://www.histedbr.fe.unicamp.br/ acer_histedbr/seminario/seminario8/_files/Ey4N6DD7.doc.>. Acesso em: 5 dez. 2013.

\section{NOTAS}

${ }^{1}$ SILVA, 2011a, p. 150.

${ }^{2}$ O Instituto Paradigma é uma Organização Social de Interesse Público (OSCIP), dedicada a desenvolver projetos para educação, trabalho e desenvolvimento comunitário, viabilizando a inclusão social das pessoas com deficiência. Presta serviços de consultoria e assessoria especializadas para empresas, setor público e terceiro setor, gerenciados com metodologia própria e compromisso com a geração de mudanças sociais. Desde o início de 2007, o Instituto Paradigma vem contribuindo para a implantação da política pública de educação inclusiva no município de Sorocaba, por meio de algumas ações como, por exemplo, o planejamento estratégico e a implantação do Centro de Referência em Educação da Secretaria de Educação, além da seleção, formação e assessoria técnica para a equipe multidisciplinar de profissionais do Centro de Referência em Educação. Fonte: Instituto Paradigma. Histórico, missão e valores do Instituto Paradigma. Disponível em: <http:// www.institutoparadigma.org.br/>. Acesso em: 20 fev. 2012.

${ }^{3}$ O IEE foi criado em março de 2001 e possui, como presidente, a ex-jogadora de voleibol Ana Moser. É uma organização civil de interesse público e beneficia-se de recursos da Lei de Incentivo ao Esporte, além de outros recursos públicos e privados. Possui, como objetivo, desenvolver a cultura esportiva em comunidades de baixa renda a partir da Educação Física e dos valores físicos, morais e éticos do esporte educacional e coordena uma série de núcleos esportivos para atendimento de crianças e adolescentes em parceria com diversas entidades. Para adentrar as redes de ensino, o IEE se vale da visibilidade de sua presidente e ex-atleta de voleibol e comercializa com as prefeituras um pacote de serviços (metodologia, kits esportivos 
com a logomarca dos patrocinadores, camisetas, shorts, agasalhos, mochilas para identificar os alunos e professores que participam do projeto). Fonte: Instituto Esporte e Educação. História. Disponível em: <http://www.esporteeducacao.org.br/>. Acesso em: 27 fev. 2012.

${ }^{4}$ Informações do portal da internet da Secretaria da Educação de Sorocaba. Disponível em: $<$ http://educacao.sorocaba.sp.gov.br>. Acesso em: 14 maio 2012.

${ }^{5} \mathrm{O}$ autor é um dos elaboradores do PCNs de Educação Física (1998b).

${ }^{6}$ Cf. também Coll et. al (2000).

${ }^{7}$ A alusão a um sujeito empreendedor constitui um dos ideais da Secretaria da Educação de Sorocaba, disseminada, desde 2006, por meio do programa intitulado Pedagogia Empreendedora. Baseando-se nas concepções de Fernando Dolabela, precursor da Pedagogia Empreendedora, a retórica anunciada é a de que nascemos empreendedores e deixamos de ser na vida adulta pela exposição a valores (anti)empreendedores na educação e nas relações sociais. Assim, a única distinção da educação empreendedora é que, para os adultos, será necessário libertar o espírito empreendedor ao passo que, para crianças, faz-se necessário impedir o aprisionamento. Como se pode notar, a Pedagogia Empreendedora apresenta-se como libertária, direcionando os sujeitos em busca de sua suposta essência empreendedora corrompida pelas relações sociais e até mesmo pelo processo de escolarização. Fonte: Prefeitura Municipal. Espaço Empreendedor. Secretaria de Comunicação da Prefeitura de Sorocaba. Disponível em: <http://agencia.prefeiturasorocaba.com.br>. Acesso em: 13 mar. 2013.

${ }^{8}$ SOROCABA. Secretaria de Educação. Marco referencial. Sorocaba: Instituto Paulo Freire, 2011. (Projeto eco-político-pedagógico).

Submetido: 02/06/2016

Aprovado: 13/12/2016

Contato:

Clayton Cesar de Oliveira Borges

FAC - São Roque/Educação Física

Rua Sotero de Souza, 104, Centro

São Roque |SP|Brasil

CEP 18.130-200 